\title{
Göktürk-2 ve Hyperion EO-1 Uydu Görüntülerinden Rastgele Orman Sinıflandırıcısı ve Destek Vektör Makineleri ile Arazi Kullanım Haritalarının Üretilmesi
}

\author{
Özlem AKAR ${ }^{* 1}$, Esra Tunç GÖRMÜŞ² \\ ${ }^{1}$ Erzincan Binali Yıldırım Üniversitesi, Meslek Yüksek Okulu, Mimarlık ve Şehir Planlama Bölümü, Harita ve Kadastro \\ Programı, Erzincan (oakar@erzincan.edu.tr) ORCID ID 0000-0001-6381-4907 \\ ${ }^{2}$ Karadeniz Teknik Üniversitesi, Mühendislik Fakültesi, Harita Mühendisliği Bölümü, Trabzon \\ (etuncgormus@ceng.ktu.edu.tr) ORCID ID 0000-0002-7667-199X
}

\begin{abstract}
$\ddot{O} \mathbf{z}$
Çalı̧̧mada spektral özellikleri birbirine yakın arazi sınıflarını birbirinden ayırarak, Göktürk-2 uydu görüntülerinden daha doğru bir arazi kullanım haritasının üretilmesi amaçlanmışıı. Bunun için Hyperion EO1 hiperspektral uydu görüntüsünün, yüksek spektral çözünürlüğünden yararlanılmıştır. Çalışma alanı olarak spektral özellikleri birbirine yakın arazi sınıflarına sahip olan Trabzon Akçaabat ilçesinin Büyükoba yaylası seçilmiştir. Çalışmada Göktürk-2 Multispektral (GMS), Göktürk-2 Pankromatik (GPAN) ve Hyperion EO-1 hiperspektral uydu görüntüleri kullanılmıştır. Öncelikle Hyperion EO-1 hiperspektral uydu görüntüsü için atmosferik ve radyometrik düzeltmeler yapılmış, bozuk ve kullanılmayan bantların temizlenmesi için bant indirgeme işlemleri uygulanmıştır. Bant indirgeme işlemi için dalgacık tabanlı Ampirik Kip Ayrıştırma (AKA) yöntemi kullanılmıştır. Sonrasında tüm görüntüler rektifiye edilerek aynı koordinat sisteminde olması sağlanmıştır. Görüntüler ön işlemden geçirildikten sonra GPAN, GMS ve indirgenmiş Hyperion EO- 1 (DHYP) görüntüleri ile Gram Schmidt (GS) ve Principle Component (PC) gibi görüntü kaynaştırma yöntemleri kullanılarak kaynaştırılmıştır. Kaynaştırma yöntemleriyle elde edilen kaynaştırılmış görüntüler üzerinden sınıflandırmada kullanılacak arazi kullanım sınıfları belirlenmiştir. Bu görüntüler yüksek sinıflandırma doğruluğu veren Rastgele Orman (RO) ve Destek Vektör Makineleri (DVM) yöntemleriyle sınıflandırılmıştır. Her bir sınıflandırma sonucu için doğruluk analizleri yapılmış ve elde edilen doğruluklar karşılaştırılmıştır. Çalışmanın sonuçları incelendiğinde, en yüksek sınıflandırma doğruluğunun, PC kaynaştırma yöntemine göre kaynaştırılmış ve RO sınıflandırıcısı ile sınıflandırılmış görüntülerden elde edildiği gözlenmiştir. PC ile kaynaştırılmış GPAN ve GMS görüntüsü ile GPAN ve DHYP' nin kaynaştırılmış görüntüsünün RO ile sınıflandırılması sonucu genel sınıflandırma doğrulukları sırasıyla $\% 72.13$ ve $\% 83.06$ olarak elde edilmiştir. Bu sonuçlara göre sınıflandırma doğruluğu \% 11 oranında artırılmıştır. Son olarak en yüksek sınıflandırma doğruluğuna sahip olan tematik görüntü kullanılarak arazi kullanım haritası üretilmiş̧tir.
\end{abstract}

Anahtar Kelimeler: Görktürk-2, Hyperion EO- 1, Rastgele Orman, Ampirik Kip Ayrıştırma, Arazi Kullanım Haritasl

\footnotetext{
* Sorumlu Yazar
} 


\title{
Producing Land Use Maps With Random Forest Classifier and Suport Vector Machines From Göktürk-2 and Hyperion EO-1 Satellite Images
}

\begin{abstract}
In this study it is aimed to produce a more accurate land use map from Gokturk-2 by separating the land classes with very similar spectral properties. Hyperion EO-1 hyperspectral satellite image with high spectral resolution was exploited in order to do that.. Büyükoba highland in Akcaabat which has land classes with very similar spectral properties was chosen as working field. Göktürk-2 Multispectral (MS), Göktürk-2 Pancromatik(PAN) and Hyperion EO-1 hyperspectral satellite images were used in this study. First of all atmospheric and radiometric corrections of hyperspectral images were done together with dimensionality reduction of unused and irrelevant bands. Wavelet based empirical mode decomposition method was used for dimensionality reduction. Then all the images were synchronized in the same coordinate system by rectification. After preprocessing steps Gokturk-2 MS and reduced Hyperion EO-1 (DHYP) were fused with Gokturk-2 Pan image by methods like Gram Schmidt (GS) and Principle Component (PC). Land classes were determined on the fused images. Then these images were classified by Random Forest (RF) and Support Vector Machine (SVM). Accuracy analysis were done for each classification results and then compared with each other. In the end it was seen that, the best classification accuracy was obtained by using RF classification method and PC fusion method. RF overall classification accuracies obtained from both fusing GPAN and GMS image with PC, and fusing GPAN and DHYP image with PC were $72.13 \%$ and $83.06 \%$, respectively. According to these results, the overall classification accuracy was increased by $11 \%$. Finally, a land use map was produced using the thematic image with the highest classification accuracy.
\end{abstract}

Keywords: Görktürk-2, Hyperion EO-1, Random Forest, Empirical Mode Decomposition, Land Use Map.

\section{GÍRIS}

Arazi kullanım haritaları, birçok bilimsel ve çevresel uzaktan algılama uygulamaları için önemli bilgiler temin etmektedir. Teknolojinin ilerlemesi ve uyduların çoğalmasıyla birlikte uydu görüntüleri bu haritaların hızlı ve güvenilir bir şekilde yapılmasına yardımcı olmaktadır (Belward,2014). Bu anlamda arazi kullanım haritalarının hızlı ve güvenilir olarak üretilmesinde görüntü sinıflandırma işlemi en yaygin kullanilan uzaktan algilama tekniklerinden biridir. Son yıllarda sağladığı yüksek doğruluk nedeniyle sıklıkla tercih edilen Rastgele Orman (RO) ve Destek vektör makineleri (DVM) gibi ileri siniflandırma yöntemleri ile optik uydu görüntülerinden, daha doğru ve büyük ölçekli arazi kullanım haritaları oluşturulabilmektedir (Tardy vd.,2017, Srivastava vd., 2012).

Görüntü sınıflandırma mevcut spektral verileri kullanarak belirli bir spektral sınıfın parçası olan pikselleri etiketleme işlemidir (Richards ve Jia, 2006). Sinıflandırma işlemi iki adımdan oluşur. Sınıflandırmada birinci adım, arazi yüzeyi olarak düşünüldüğünde orman, su, çayır-çimen alanları, toprak gibi farklı arazi yüzeylerini içeren sınıfları tanımlamaktır. İkinci aşama ise seçilen sınıflara göre piksellerin etiketlenmesi işlemidir. $\mathrm{Bu}$ işlemlere sinıflandırma ve etiketleme denilmektedir (Mather, 2004).

Sınıflandırmada en yaygın olarak karşılaşılan sorunlardan biri de optik görüntülerin spektral çözünürlüklerinin multispektral görüntülerdeki benzer spektral özelliklere ait sinıfları birbirinden ayırmada yetersiz olmasıdır. $\mathrm{Bu}$ tarz problemlerin cevabı başka kaynaklardan gelen uydu görüntülerinin özelliklerini tamamlayıc1 bilgi olarak kullanarak, multispektral görüntülerin sınıflandırılmasının iyileştirilmesidir. Buna en iyi örnek spektral 
çözünürlüğü yüksek olan hiperspektral uydu görüntüleridir. Farkl1 uydu görüntülerinin kaynaştırılması ile tek bir görüntüden elde edilemeyecek bilgiler elde edilir, bilgi çıkartımı yapılır ve karar verme mekanizmaları geliştirilir (Lahat vd., 2015).

Literatüre bakıldığında arazi kullanım haritalarının üretimi için farklı uydu görüntüleri kullanılarak bir çok çalışmanın yapıldı̆̆ 1 görülmektedir. Örneğin, optik uydu görüntülerinden Landsat5 ve 8' e ait olan görüntüler sıkça hassas arazi kullanım haritası üretmek için kullanılmaktadır (Inglada vd., 2015). Bunun yanı sira Sentinel 2'ye ait görüntülerin de başarı ile kullanıldığı görülmektedir (Immitzer vd., 2016).

Çalışmada kullanılan Göktürk-2 uydu görüntüsünü sağlayan uydu, Türkiye'nin ikinci uydusudur ve 18 Aralı 2012 tarihinde firlatılmıștır (Teke, 2014). Șimdiye kadar detay çıkartımı (Başak ve Yıldırım, 2017) ve bitki ayırımı (Kalkan vd. 2015) gibi birçok uygulamada kullanılmıştır. Bu çalışmada ise Göktürk-2 uydu görüntüsünün arazi kullanım haritalarının üretimindeki başarısı test edilmiştir. Bunun için öncelikle, küçük ve birbirine yakın spektral özellikteki objeleri birbirinden daha iyi ayırt edebilmek için hem konumsal hem de spektal çözünürlüğü iyi görüntü elde etmek amaciyla, konumsal çözünürlüğü $2.5 \mathrm{~m}$ olan Göktürk-2 PAN uydu görüntüsü, spektral çözünürlüğü yüksek, indirgenmiş Hyperion EO-1(DHYP) hiperspektral uydu görüntüsü ile kaynaştırılmıştır. Daha sonra yüksek sınıflandırma doğruluğu sağlayan RO sınıflandırma yaklaşımı ile spektral özellikleri birbirine yakın arazi sinıflarını birbirinden ayırarak arazi kullanım haritası üretilmiştir.

\section{1. Çalıșma Alanı ve Veri setleri}

Çalışma alanı olarak seçilen Büyükoba yaylası, Türkiye' nin Doğu Karadeniz Bölgesinde yer alan Trabzon ili Akçaabat ilçesinde yer almaktadır. Çalışma alanı 2091 hektarlık bir alanı kapsamaktadır (Şekil 1). Çalışmada Göktürk-2 Multispektral (MS), Göktürk-2

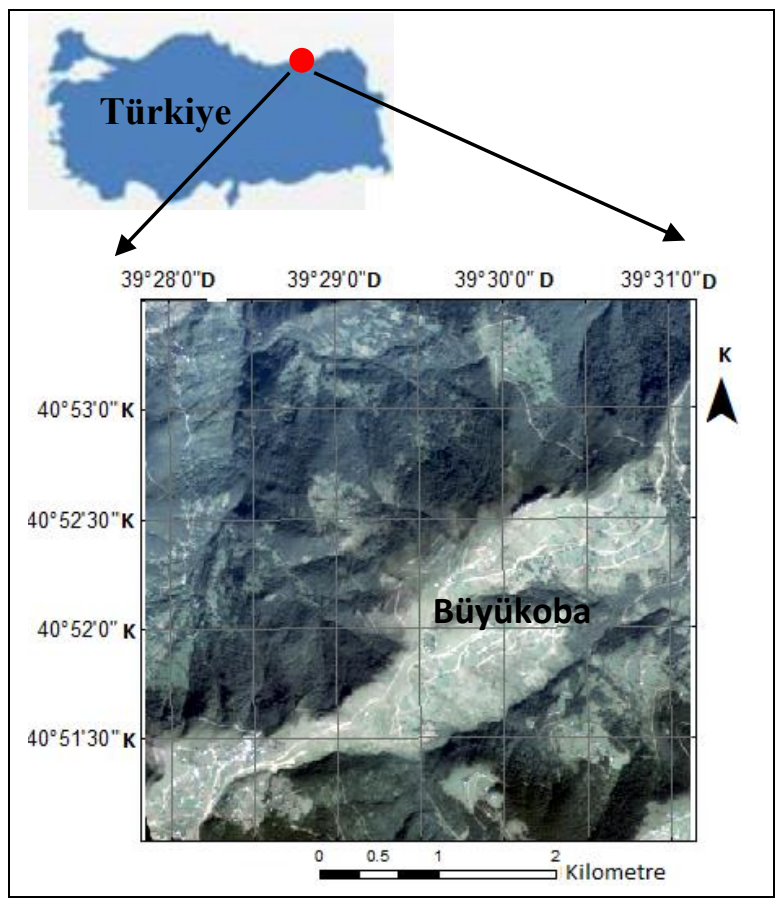

Şekil 1. Çalışma Alanı

Pankromatik (PAN) ve Hyperion EO-1 hiperspektral uydu görüntüleri kullanılmıştır (Şekil 2). Çalışmada kullanılan Göktürk-2 uydu görüntüsü, $5 \mathrm{~m}$ konumsal çözünürlüklü 4 adet Multispektral banda (Kırmızı, Yeşil, Mavi ve Kız1lötesi) ve $2.5 \mathrm{~m}$ konumsal çözünürlüklü 1 adet PAN banda sahiptir. Kızılötesi bant çalışma alanını kapsamadığ1 için kullanılmamıştır. Hyperion EO-1 hiperspektral uydu görüntüsü ise 220 adet spektral banda ve 30 konumsal çözünürlüğe sahiptir.

Çalışma alanı, mera ve orman, toprak yollar ve toprak, binalar ve beton yollar olmak üzere birbirine spektral olarak benzer özellikteki arazi kullanım sınıflarını içermektedir. Göktürk-2 uydu görüntüsü gibi bant sayıs1 düşük bir görüntüyle bu sınıfları birbirinden ayırmak zor olmaktadır. Bant sayısı fazla ve konumsal çözünürlüğü iyi bir görüntü kullanılması halinde yakın spektral özellikli sinıfları birbirinden ayırt edebilmek daha mümkün olmaktadır. $\mathrm{Bu}$ nedenle yakın spektral özellikteki sinıfları birbirinden daha iyi ayırararak sınıflandırma doğruluğunu artırmak için Hyperion EO-1 hyperspektral uydu görüntüsünün spektral bantlarından ve Göktürk-2 uydu görüntüsünün konumsal çözünürlüğünden yararlanılmıştır. 


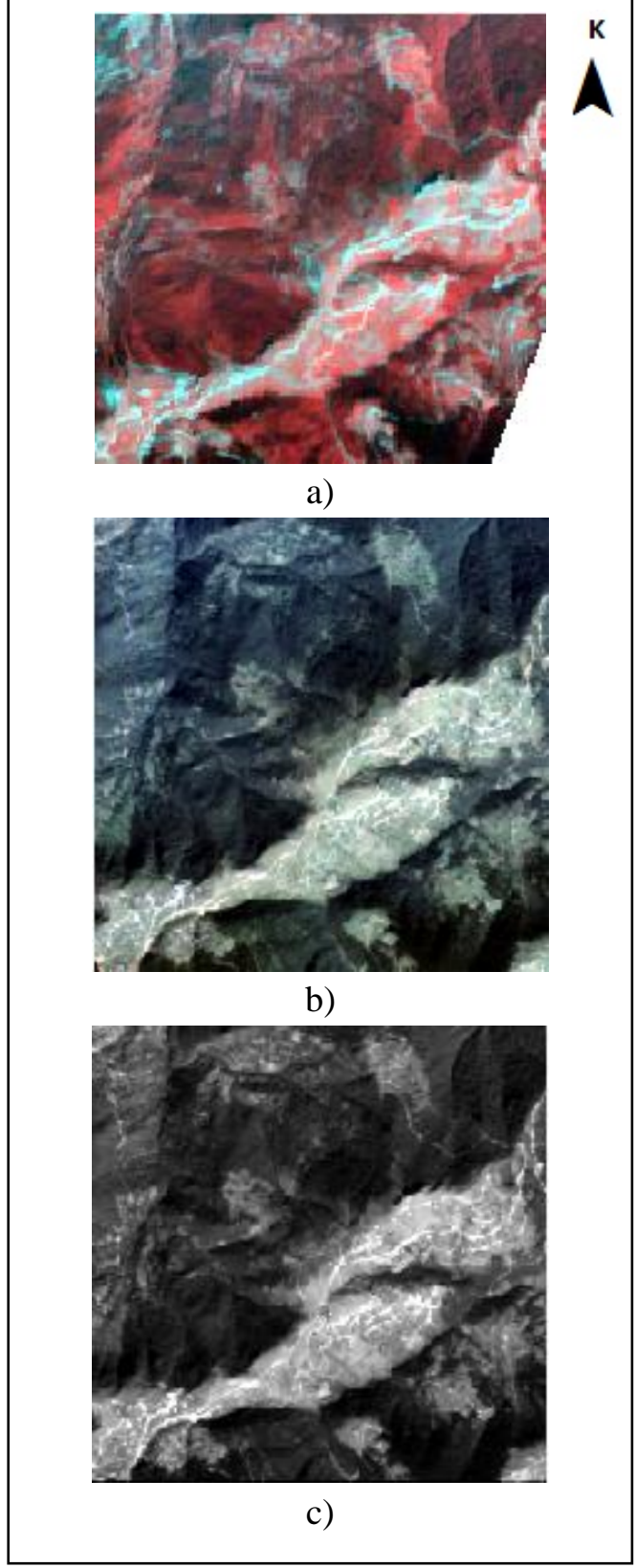

Şekil 2. Kullanılan uydu görüntüleri a) Hyperion EO-1, b) Göktürk-2 MS, c) Göktürk2 PAN

\section{YÖNTEM}

$\mathrm{Bu}$ bölümde çalışmada boyut azaltmak ve sınıflandırma yapmak için kullanılan yöntemler kısaca açıklanmıştır.

\subsection{Dalgacık Dönüşümü (DD)}

Dalgacık dönüşümü görüntüler içerisindeki değişimleri analiz eden etkili bir yöntemdir. Geleneksel yöntemler ile karşılaştırıldığında sinyalin orijinal yapısını bozmadan kolayca işlem yaptığı görülmektedir. Dalgacık analizi bir sinyale ölçek ve zaman perspektifinden bakmayı sağlamaktadır (Abbak, 2007). Ölçek ile sinyalin yerel düzenliliği ve zaman ile değişimin oluşum anı hakkında bilgi verdiği için fourier ve gabor gibi diğer dönüşümlere göre daha avantajlı olduğu görülmektedir. Dalgacık dönüşümü sürekli ve ayrık olmak üzere iki ana başlığa ayrılmaktadır. Dalgacık fonksiyonunun kaydırılıp bir ölçekle çarpıldıktan sonra zaman alanı boyunca toplanmasıyla sürekli dalgacık dönüşümü gerçekleştirilir. Tüm ölçek aralığında yapılacak dalgacık analizi sonucu çok büyük veri yığınları oluşmaması için analist belirli ölçek grupları tespit eder ve bu aralıkta analizleri yapmaktadır. Çoğunlukla en pratik ve kullanışlı yol, ölçek ve konum değerleri ikinin kuvveti olacak şekilde seçilmesidir. Bu işleme ayrık dalgacık dönüşümü adı verilmektedir (Abbak. 2007).

$\mathrm{Bu}$ çalışmada ayrık dalgıcık dönüşümü'nü hesaplarken ana dalgacık olarak Daubechies 3 (db3) (Chen,2009) ve indirgeme seviyesi olarak 4 alınmıştır. Dalgacık dönüşümünden sonraki sinyalin uzunluğu dalgacık filtresinin ve orijinal sinyalin uzunluğuna bağlidır. Dalgacık dönüşümü tabanlı boyut azaltımı hangi bileşenlere ait katsayıları (alçak frekans, yüksek frekans ya da her ikisi) seçecekse, ona göre değişmektedir. Bu çalışmada Dalgacık dönüşümü yapıldıktan sonra boyut azaltım amaçlı katsayılar seçimi doğrusal dalgacık öznitelik çıkartımına göre yapılmıştır (Tunç Görmüş vd., 2012) .

\subsection{Ampirik Kip Ayrıştırma (AKA)Yöntemi}

AKA dönüşümü diğer dönüşümlerin aksine bir sınırlama parametresinin ve veri hakkında önceden bir varsayımı olmamasından dolayı görüntü analizinde tercih edilmeye başlanmıştır. AKA ile görüntü İçkin Kip Fonksiyonlarına (IKF) ve bir kalana ayrılır (Huang ve ark. 1998). Daha sonra elde edilen IKF' leri, kalan ile birlikte toplayarak bilgi kaybı ve hata olmadan orijinal işaret elde edilir.

AKA, görüntünün konumsal frekansını IKF' ler ile ifade eder. İlk İKF görüntünün en yüksek lokal konumsal frekanslarını göstermektedir. İkinci İKF, ikinci en yüksek konumsal frekansları göstermektedir ve bu 
böyle devam etmektedir. İKF olabilmek için 2 şart vardır. Birincisi, sıfır geçişlerinin sayısının, uç noktasının sayısına eşit olması ya da aralarındaki farkın 1 olmasıdır. Diğeri ise, lokal maksimum ve lokal minimum değerlerinin belirlediği zarfların ortalama değerlerinin herhangi bir noktada sifir olmasıdır. Üst zarf, işaretin yerel maksimum noktalarının ara değerlemesi ile, alt zarf yerel minimum noktalarının ara değerlemesi ile bulunmaktadır. AKA, sinyalin istatistiklerine bağlı değildir ve sadece sinyalin lokal özelliklerine dayanmaktadır. Frekanslar içi ve frekanslar arası birçok öznitelik oluşturmaktadır.

Bir bandın İKF' lerini bulan iteratif işlemlere 'eleme işlemi' adı verilmektedir. Bu işlem bandın kendisi $\left(B_{1}\left(i_{s} j\right)\right)$ ile başlamaktadır.

$I_{l, 1}^{(1)}=B_{1}(i, j) I_{l, m}^{(n)}$

[1]' de (n) iterasyon sayısını, $1=1,2, \ldots$ L band sayısın1, L hiperspektral görüntüdeki toplam görüntü sayısını, $(\mathrm{i}, \mathrm{j})$ uzamsal boyutu, $\mathrm{m}=1: \mathrm{M}$, M İKF sayısını temsil etmektedir.

Buna göre 2D-AKA'nın nasıl çalıştığ 1 , hiperspektral görüntünün 1 numaralı band $B_{l}(i, j)$ için, birinci İKF'nin ( ${ }^{[} K F_{l, m}$ ) nasıl bulunduğu aşağıdaki gibi açıklanmıştır;

1) Girdi görüntüde tüm yerel maksimum ve yerel minimum noktalarının 2B genlik ve pozisyonlarının elde edilmesi.

2) Eğri ara değerlenmesi ile yerel maksimum noktalarından 2B üst zarf $E_{\max }\left(i_{i} j\right)$ ve yerel minimum noktalarından 2B alt zarf $E_{\min }(i, j)$ olușturulmas1.

3) Her $(i, j)$ uzamsal pozisyon için üst zarf ve alt zarfin ortalamasının hesaplanmasi [2]

$E M_{m}^{n}(i, j)=\left(E_{\max }\left(i_{j}, j\right)+E_{\min }(i, j)\right) / 2[2]$

4) Ortalama zarf işaretinin, giriş işaretinden çıkarılması [3]

$S_{m}^{n}(i, j)=I_{l, m}^{n}(i, j)-E M_{m}^{n}(i, j)$

Buraya kadarki adımlar eleme işleminin bir iterasyonunu göstermektedir.
5) Bu adımda yapılacak olan, 4. adımda elde edilen görüntünün IKF olup olmadığını test etmektir. İKF olma şartı zarf ortalama işaretinin sıfıra yeterince yakın olup olmamasına bağlıdır[4] (Demir ve Erturk, 2010).

$\sum_{i=l}^{P} \sum_{j=l}^{R}\left|E M^{n}(i, j)\right| /(P$ * $R)<\tau$

Burada $\mathrm{P}$ ve $\mathrm{R}$ ortalama zarfin boyutları, ${ }^{\tau}$ ise sıfıra yakın bir değerdir. Eğer durdurma kriteri iterasyonda sağlandıysa $(n=N)$, ilk İKF elde edilmiş olur, ${ }^{\mathrm{I} K} F_{l, m}\left(i_{i}, j\right)=S_{m}^{N}\left(i_{i}, j\right) \times$ Eğer bu kriter sağlanmadı ise, ilk İKF bulunana kadar, adım 4'te elde edilen görüntü adım 1'de girdi görüntü olarak ele alınıp işlemler tekrar edilir [5],

$I_{l, m}^{n+1}\left(i_{i} j\right)=S_{m}^{n}(i, j)$

6) Eğer İKF başarılı bir şekilde elde edildiyse, kalan sinyal hesaplanır

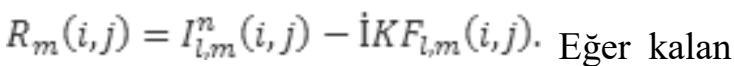
sinyal daha fazla uç nokta içermiyorsa AKA işlemi sona erer. Eğer içeriyorsa, bir sonraki İKF'nin hesaplanmasına, bu kalan görüntünün birinci adımda girdi görüntü olarak ele alınması ile devam edilir [6], $I_{l, m}^{m+1}\left(i_{i}, j\right)=R_{m}\left(i_{i}, j\right)$

Orijinal bant $B_{l}\left(i_{j} j\right)$, tüm IKKF'lerin ve en son kalanın toplanması ile tam olarak geri elde edilmektedir [7].

$B_{l}\left(i_{i}, j\right)=\sum_{m=l}^{M} I K F_{l, m}\left(i_{, j}\right)+R_{M}\left(i_{i}, j\right)$

Bu çalışmada 2D-AKA, 0.006 durdurma kriteri ve 9x9 pencere kullanılarak yapılmıştır.

Boyut indirgemek için ise bu iki yöntem birlikte kullanılmış, sonuçta ana veriyi daha iyi özetleyen yeni bir bant alt kümesi oluşturulmuştur. İndirgeme yöntemi k1saca aşağıda özetlenmiştir (Tunç Gormus vd., 2017). 
1. 2B-AKA'nın her bir spektral banda uygulanması ve $\mathrm{M}$ derece IKF özniteliklerinin oluşturulması,

2. Elde edilen her bir İKF özniteliklerindeki piksellere spektral uzayda 1B-DD uygulanması, DíKF'lerin elde edilmesi,

3. Düşük seviye DİKF'leri toplayarak yeni dalgacık tabanlı IKKF'lerin oluşturulması. Örneğin DİKF1 ve DİKF2 toplayarak DİKF12 elde edilmesi [8],

$W i K F\left(1_{p} . M\right)\left(i_{j} j\right)=\sum_{m=1}^{M} W i K F_{m}\left(i_{j} j\right)$

4. Son olarak, dalgacık dönüşümünün tipine göre istenildiği kadar öznitelik seçilerek sinıflandırmaya girecek DİKF özniteliklerinin belirlenmesi Tunç Görmüş vd., (2012).

\subsection{Rastgele Orman (RO) Sinıflandırıcısı}

Günümüzde RO algoritması, sınıflandırmada çok iyi performans sergilediği için görüntü sinıflandırmada siklikla tercih edilmektedir (Akar ve Güngör, 2015). RO, ağaç tipi sinıflandirıcilar topluluğudur (Breiman, 2001). Breiman ve Cutler (2005) RO' yu, şuan ki algoritmalar arasında doğruluğu eşsiz olan bir sınıflandırıcı olarak tanımlamıştır. Ayrıca hızlı ve belirli bir kalıbı olmayan bir yöntem olduğunu söylemektedir. $\mathrm{Bu}$ yöntemde ne kadar istenirse o kadar ağaçla çalışılır (Breiman ve Cutler 2005). RO yönteminde, $\left\{h\left(x, \theta_{K}\right) k=1, \ldots\right\} \quad$ şeklinde ağaç tipi sinıflandırıcılar kullanmaktadır. Burada, $x$, girdi verisini; $\theta_{K}$, rastgele vektörü temsil etmektedir (Breiman, 2001; Breiman, 2009).

RO yönteminde, öncelikle gerçek veri setinden yer değiştirmeli olarak yeni bir eğitim veri seti oluşturulur. Ardından, rastgele özellik seçimi kullanılarak yeni eğitim setinden bir ağaç geliştirilir. Geliştirilen ağaçlar budanmaz (Archer, 2008; Beriman, 2001).

RO sınıflandırıcısı ile bir ağaç üretmek için kullanıcı tarafindan tanımlanan 2 parametre gereklidir. Bu parametreler, en iyi bölünmeyi belirlemek için her bir düğümde kullanılan değişkenlerin sayısı $(m)$ ve geliştirilecek ağaçların sayısı $(N)$ 'dir (Pal, 2005).Kullanıcı tarafından başlangıç $m$ değeri rastgele seçilir sonraki $m$ 'ler genelleştirilmiş hatalara (OBB) göre artırılır ya da azaltılır. $m$ azalınca korelasyon ve güç azalır, $m$ artınca korelasyon ve güç artar. Bu şekilde en uygun $m$ bulunur ve siniflandırma duyarlığı artar, hata azalır. Breiman, (2002)'a gore, $m$ değişken değeri seçilirken, $m$ değerinin $M$ (toplam değişken sayısı) değişkeninin kareköküne eşit olarak alınması genellikle optimum sonuçlar verir. RO' da tüm girdi değişkenleri kullanılmamaktadır. RO algoritmasının hesap karmaşıklığını sadeleştirmek ve ağaçlar arasındaki korelasyonu azaltmak amacıyla bir $m$ değeri seçimi yapılmaktadır. $\mathrm{Bu} m$ değeri, sınıflandırmada önemli olan değișken sayısını ifade etmektedir. (Chen, 2008). $T$ eğitim verisinden $T_{k}$ yer değiştirmeli yeni eğitim verisi üretilir. Yeni eğitim veri seti kullanılarak $h\left(x, T_{k}\right) \quad$ sinıflandirıcisı oluşturulur.

Sınıflandırıcı ile çantaya atılmış tahminlerden oylama yapılır. Eğitim verisindeki her $x, y$ için sadece bu sınıflandırıcı ile oylama gerçekleşir. $T_{k}, x$ ve $y^{\prime}$ yi içermez. (Beriman, 2001).

RO en büyük boyutta ağaç geliştirmek için kullandığı CART (Classification and Regression Tree) algoritmasında, bir dügümde belirli bir ölçüt uygulanarak bölünme işlemi gerçekleştirilir (Özkan, 2008). Bölünme işlemlerinde homojen sınıf dağılımına sahip düğümler tercih edilir. Düğüm homojenliğinin ölçümünde RO yöntemi, Gini indeksini kullanmaktadır. Verilen bir $T$ eğitim veri seti için rastgele bir örnek (piksel) seçilsin ve bu örnek $C_{i}$ sinıfina ait olsun. Bu duruma göre Gini indeksi şöyle ifade edilir (Eşitlik 9);

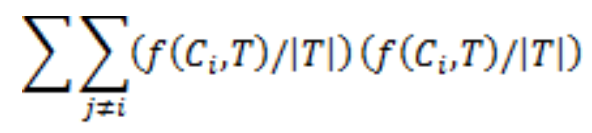

Eşitliğinde [1], $f\left(C_{i}, T\right) /[T \mid$ seçilen örneğin $C_{\tilde{i}}$ sınıfına ait olma olasılığını gösterir (Pal,2005). Gini indeksi büyüdükçe sınıf heterojenliği artarken, Gini İndeksi azaldıkça sınıf homojenliği artar. Bir alt düğümün Gini indeksi bir üst düğümün Gini indeksinden daha az olduğunda o dal başarılıdır. Gini indeksi sıfıra ulaşınca yani her bir yaprak düğümde bir 
sınıf kaldığında ağaç dallanma işlemi sonlanır (Watts, vd., 2011). Kaç tane ağaç üretmek istenirse her düğüm için en iyi dal belirlenerek o kadar ağaç üretilir (Liaw ve Wiener,2002). Şeki13, RO sınıflandırıcısının ağaç yapısını özetlemektedir. Şekildeki $x_{i j}$, girdi verilerini temsil etmektedir.

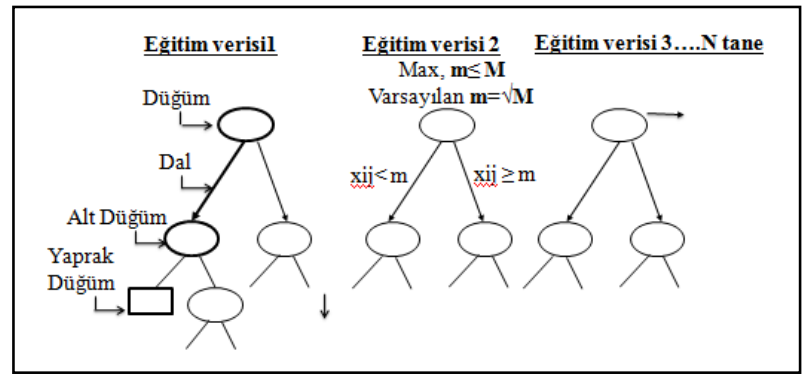

Şekil 3. RO sınıflandırıcısına ait ağaç yapısı

Ağaç gelişiminden sonraki aşama, girdi verisinin sınıflandırılması ișlemidir. $\mathrm{Bu}$ işlemde RO, girdi verisini ormandaki her bir ağaca yerleştirir. Belirlenen ağaçlar arasında oylama yapılır ve en çok oyu alan ağaç bir sinıfa atanır (Liaw ve Wiener, 2002).

\subsection{Destek Vektör Makineleri}

Son yillarda sınıflandırma doğruluğunu ciddi derecede artırdığı için uzaktan algılama uygulamalarında makine ögrenme yöntemi gibi parametrik olmayan yöntemler siklıkla tercih edilmektedir ki Destek Vektör Makineleri (DVM) bunlardan biridir (Thanh Noi ve Kappas, 2018). Bu yöntem, hem doğrusal olarak birbirinden ayrilabilen (lineer olan) hem de doğrusal olarak birbirinden ayrilamayan (lineer olmayan) verileri sınıflandırabilir. Amaç sınıfları birbirinden ayıran optimum hiper düzlem belirlenmesidir (Vapnik, 1995). Eğer şekil 4'te gösterilen siniflar birbirinden doğrusal olarak ayrılabiliyorsa, sınıflar1 birbirinden ayıran düzlemlerden mesafesi en büyük olan düzlemleri belirler ve bu düzlemleri kullanarak doğrusal bir ayırt edici fonksiyon oluşturur. Lineer fonksiyonlarla siniflar birbirinden ayrılır. Bu sinıflar doğrusal olarak ayrilamiyor ise siniflandirma hatasinı minimum, düzlemler arası mesafeyi maksimum yapmayı sağlayacak pozitif bir $C$ parametresi ve kernel fonksiyonları kullanılarak sinıfların doğrusal olarak ayrılabildikleri daha yüksek boyutlu başka bir uzaya taşınırlar. Bu uzayda sınıflandırma işlemi gerçekleşir (Özkan, 2008; (Tso ve Mather, 2009; Stephens ve Diesing; 2014, Çölkesen ve Yomralığlu, 2014). İyi performans gösterdiği için en yaygın kullanılan kernel fonksiyonu Radyal tabanl fonksiyondur. (Thanh Noi ve Kappas, 2018; Kavzoglu ve Çölkesen 2009).

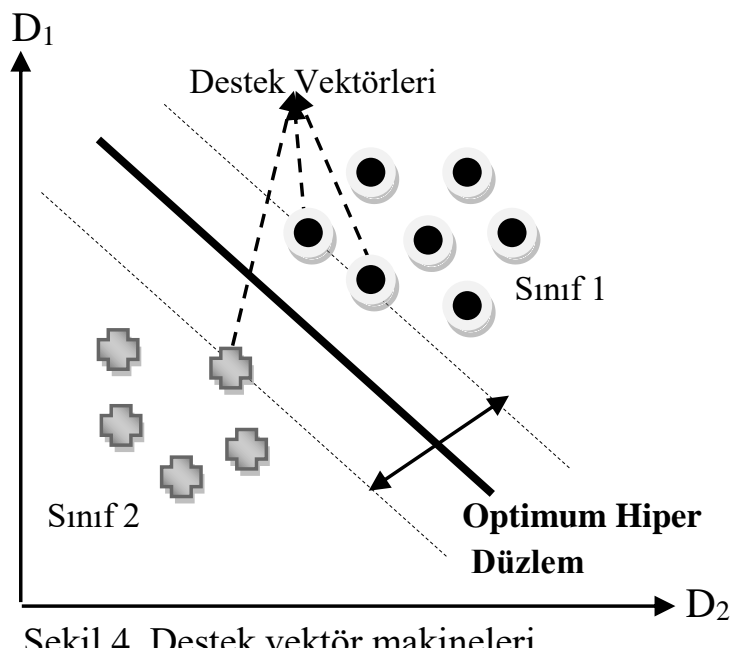

\section{UYGULAMA}

Hyperion EO 1 hiperspektral görüntüsü, kaynaştırma işlemlerinde kullanılmadan önce L1R formatında indirilerek ilgili çalışma alanı kesilmiştir. 242 banttan bozuk bantlar çıkartıldıktan sonra 175 bant kalmıştır. ENVI yazılımı kullanılarak sirasıyla Radyometrik düzeltme ile radyans ve FLAASH düzeltmesi ile reflektans formuna dönüştürülmüştür. 


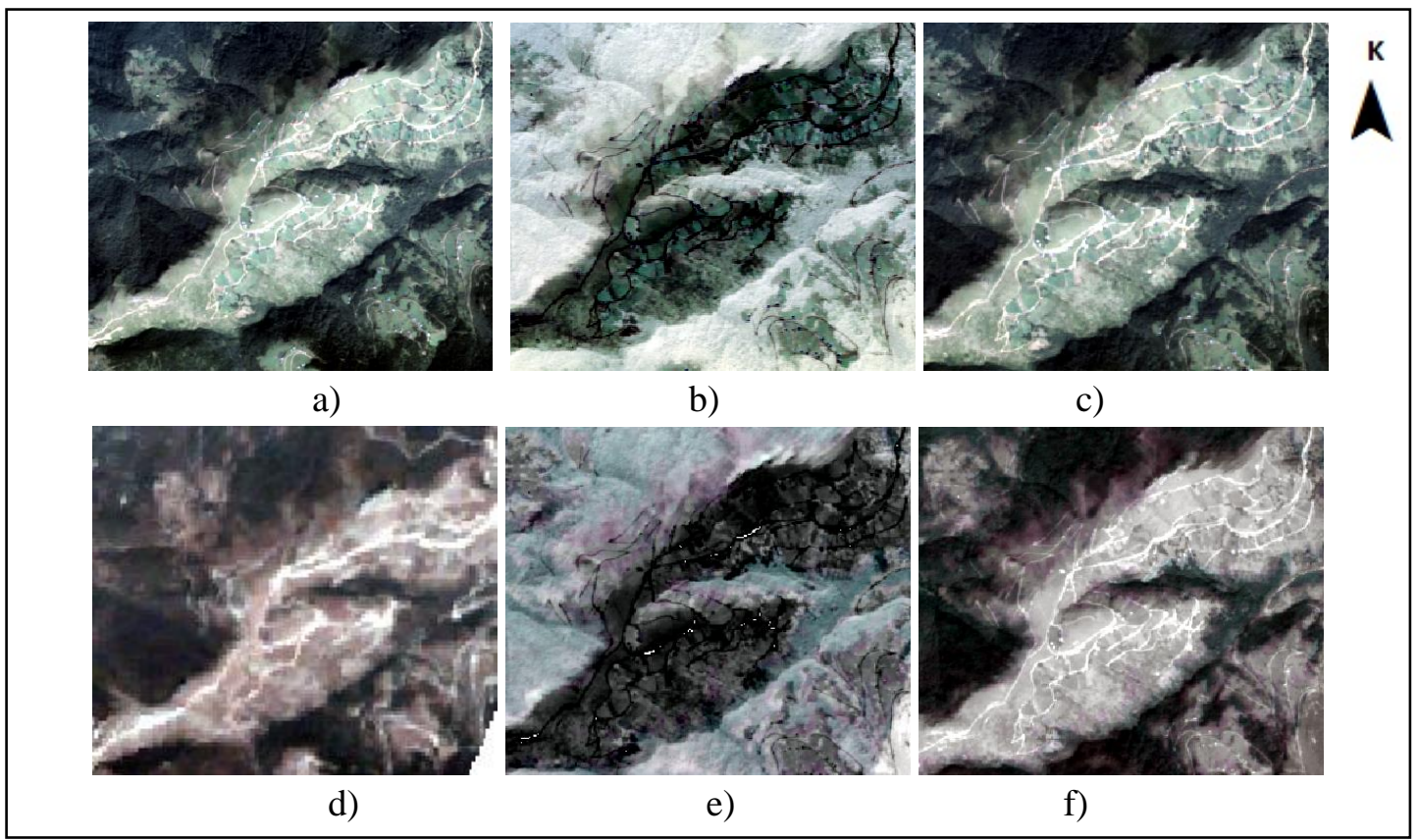

Şekil 5. Orjinal ve Kaynaştırılmış görüntüler a) GMS b) PC_GMS_GPAN, c) GS_GMS_GPAN, d) DHYP e) PC_DHYP_GPAN, f) GS_DHYP_GPAN

Bozuk bantların manuel olarak çıkartılmasından sonra, hiperspektral görüntüye boyut indirgeme yöntemi uygulanmıştır. Boyut indirgeme işlemi Hiperspektral görüntülerin işlenmesi sırasında yapılması gereken ön işlem adımlarından biridir. Çok sayıda komşu ve dar bantlara sahip olması görüntünün çok sayıda tekrar eden bilgi içermesine neden olmaktadır. Bu durum hem kullanıcıyı, hem de uygulamanın başarımını olumsuz etkilemektedir. Dolayisı ile bu çalışmada da boyut indirgeme yöntemleri kullanarak uygulamanın sonucunu iyileştirecek en iyi bantlar seçilmiş ve onlar ile işlemlere devam edilmiştir. Bu çalışmada Tunç Görmüş vd. (2012) önerdiği Dalgacık dönüşümü tabanlı Ampirik Kip Ayrıştırma (AKA) yöntemi (DAKA) kullanılarak hiperspektral görüntülerin boyutu azaltılmış ve görüntüyü en iyi özetleyen öznitelik alt kümesi bulunmuştur.

İki boyutlu (2B) AKA dönüşümü kullanarak konumsal bilgiden, bir boyutlu (1B) ayrik dalgacık dönüşümü (DWT) kullanarak ise spektral bilgiden yararlanılmaktadır. Diğer yöntemlere göre başarılı olmasının nedeni de hem spektral, hem konumsal bilgiden aynı anda yararlanıyor olmasidır. $\mathrm{Bu}$ indirgeme işlemiyle birlikte Hyperion EO- 1 görüntüsü 14 banda indirgenmiştir.
Daha sonraki aşamada, kullanılacak görüntülerin aynı koordinat sisteminde olmaları için ERDAS Imagine yazılımı kullanılarak Görktürk-2 MS ve Hyperion EO1 görüntüleri Göktürk-2 PAN uydu görüntüsüne göre geometrik olarak düzeltilmiştir. Bu şekilde uydu görüntülerinin ön işlemi tamamlanmıştır.

Ön işlemden sonra diğer bir aşama da Şekil 5 'de görülen görüntülerin kaynaştırılması işlemidir. Görüntülerdeki arazi kullanım sınıflarını daha iyi yorumlayabilmek için, ENVI yazılımında $5 \mathrm{~m}$ konumsal çözünürlüklü Görktürk-2 MS ve $30 \mathrm{~m}$ konumsal çözünürlüklü Hyperion EO-1 uydu görüntüleri, Görktürk-2 PAN görüntüsüyle, GS ve PC gibi görüntü kaynaştırma yöntemleri kullanılarak kaynaştırılmıştır. Bu işlem sonucunda $2.5 \mathrm{~m}$ konumsal çözünürlüklü görüntüler elde edilmiştir.

Sınıflandırma işlemi için kaynaştırılmış görüntüler üzerinden 6 adet arazi kullanım sinıfi (mera, yol, orman, toprak, gölge ve bina) belirlenmiştir. ENVI yazılımında her sınıf için görüntüler üzerinden sinıflara ait örnek pikseller toplanmıştır. Mera, yol, orman ve toprak sınıfları için yaklaşık 1300 piksel, çalışma alanında daha az kullanım alanına sahip olan gölge ve bina sınıfları için ise daha az sayıda piksel toplanmıştır. Toplamda 
görüntü üzerinden 6408 eğitim pikseli toplanmıştır. Sonrasında ENVI yazılımında DVM siniflandirıcisı yardımıla optimum siniflandirma parametresine $(C)$ ve Radyal tabanlı fonksiyona göre tüm

kaynaştırılmış görüntüler sınıflandırılmıştır. $C$ parametresi kullanıcı tarafindan görüntülere göre denenerek belirlenmiştir. Sonrasında Matlab yazılımında her bir görüntü üzerinde seçilen bu örnek alanlara göre eğitim ve test verileri Rastgele Özellik Seçim Metodu kullanılarak oluşturulmuştur. Görüntüler üzerinden toplanan 6408 pikselin 3204'ü eğitim verisi, kalan 3204'ü test verisi olarak seçilmiştir ve RO sınıflandırıcısı ile görüntüler, kullanic1 tarafindan belirlenen optimum parametrelere $(m$ ve $N)$ göre sınıflandırılmıştır (Örn. Şekil 6).

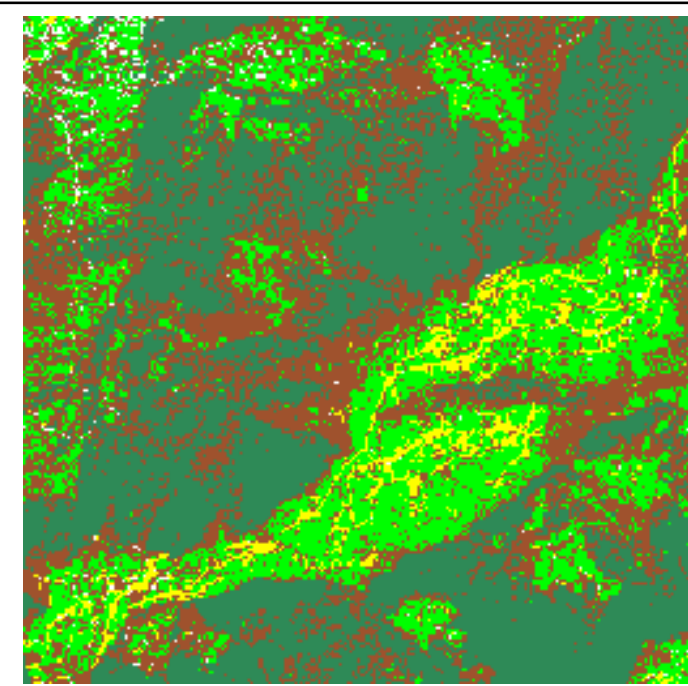

a)

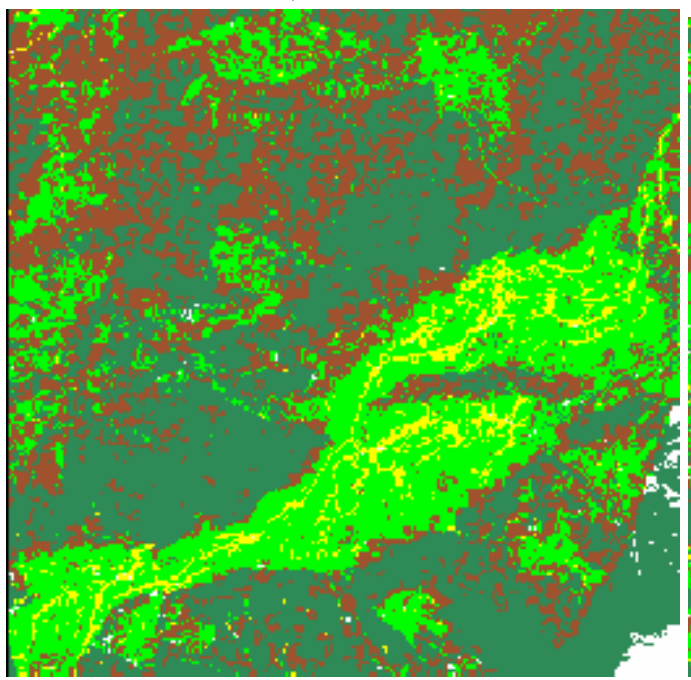

c)

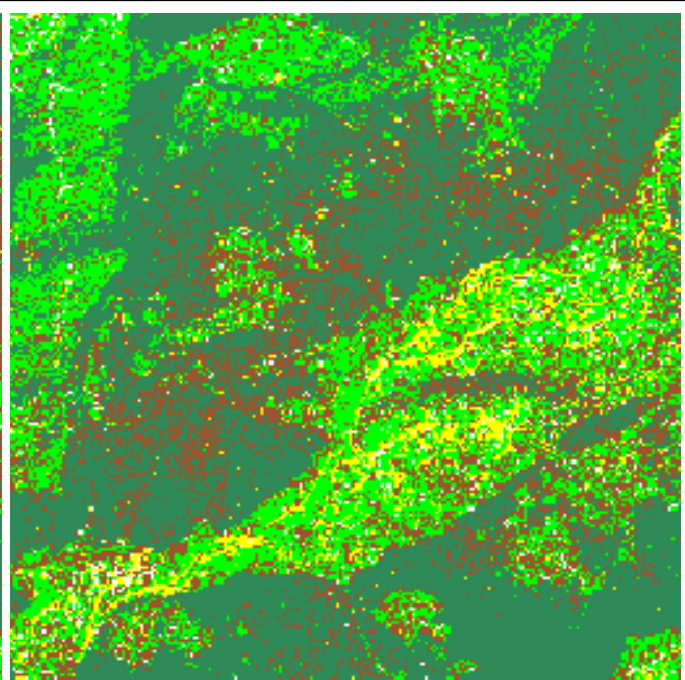

b)

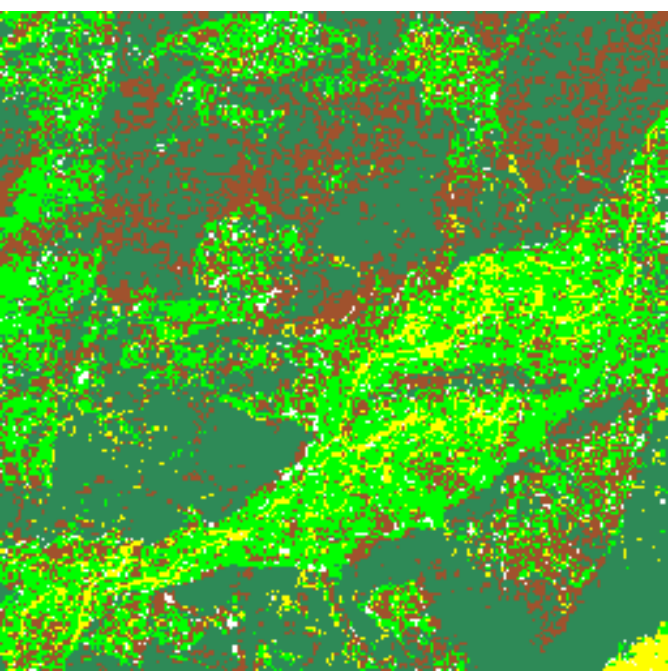

d)

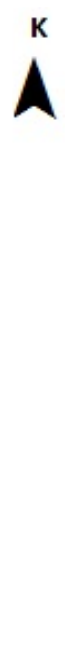

OOrman OMera OYol

Toprak OBina

Şekil 6. Sinıflandırılmış görüntüler a) DVM_PC_GMS_GPAN, b) RO_PC_GMS_GPAN, c) DVM_PC_DHYP_GPAN, d)RO_PC_DHYP_ $\overline{G P A N}$ 
DVM ve RO için aynı eğitim alanları kullanılmıştır. Gölge sınıfı sadece ormanlık alanlarda olduğu için sinıflandırma sonucu elde edilen 8 adet tematik görüntüde orman sınıfı gölge sınıfiyla birleştirilmiştir.

Her bir sinıflandırma sonucunun doğruluğu, en yaygin kullanilan siniflandirma sonras1 doğruluk analizleri yöntemlerinden biri olan hata matrisi kullanılarak değerlendirilmiştir. $\mathrm{Bu}$ matris kullanılarak, bilinen referans veriler (yer gerçeği) ile buna karşıllı gelen otomatik siniflandırma sonucu elde edilen sonuçlar arasındaki ilişkiler kategorik olarak birbirleriyle karşışş̧ırılabilmektedir. (Lillesand, vd. 2004). Çalışmada 5 sınıf için, her bir görüntü üzerinde, sinıfların kapladıkları alanlara göre nokta üreten stratified random yöntemi kullanılarak her sınıf için en az 30 nokta olacak şekilde toplamda 183 nokta üretilmiştir. $\mathrm{Bu}$ noktalar kullanılarak sınıflandırılmış tematik görüntülerin doğrulukları analiz edilmiştir. Her bir sinıflandırma sonucu için hata matrisleri oluşturulmuştur (Tablo 1).

\section{BULGULAR ve TARTIŞMA}

RO sınıflandırıcısının DVM yöntemine göre performansını değerlendirmek için doğruluk analizleri sonucu elde edilen hata matrisleri incelenmiştir. Öncelikle PC_GMS_GPAN ve GS_GMS_GPAN kaynaştırılmış görüntüleri siniflandiran RO'nun hata matrislerine bakıldığında sirasıyla \%72.13 ve \% 69.40 genel sinıflandırma doğrulukları ve $\kappa(0.72)$, $\kappa$ (0.69) kappa olarak elde edilmiştir. DVM' nin hata matrislerine bakıldığında aynı görüntüler için sırasıyla \%65.57 ve \% 65.03 genel sınıflandırma doğrulukları ve $\kappa(0.65)$, $\kappa$ (0.65) kappa olarak elde edilmiştir. Bu sonuçlara göre RO'nun, DVM' den daha iyi performans sergilediği görülmüștür. Ayrıca PC kaynaştırma yönteminin de GS' den daha iyi sınıflandırma sonucu verdiği gözlemlenmiştir.

Tablo 1. Siniflandirma sonucu elde edilen hata matrisleri a) RO_PC_GMS_GPAN b) RO_PC_DHYP _GPAN

\begin{tabular}{|c|c|c|c|c|c|c|c|c|c|}
\hline & & & & & & & & & \\
\hline & & $\stackrel{\frac{\pi}{0}}{\Sigma}$ & $\vec{\partial}$ & Е్ & 苛 & 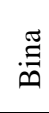 & $\begin{array}{l}\Xi_{\Xi}^{\Xi} \\
\text { : } \\
\text { W }\end{array}$ & $\begin{array}{l}0 \\
0 \\
0\end{array}$ & $\widehat{d}$ \\
\hline & Mera & 23 & 2 & 0 & 6 & 4 & 35 & 56.10 & 65.71 \\
\hline & Yol & 1 & 21 & 0 & 0 & 3 & 25 & 80.77 & 84.00 \\
\hline 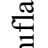 & Orman & 0 & 0 & 60 & 4 & 0 & 64 & 75.95 & 93.75 \\
\hline$\stackrel{\Xi}{\bar{n}}$ & Toprak & 16 & 2 & 19 & 15 & 3 & 55 & 57.69 & 27.27 \\
\hline & Bina & 1 & 1 & 0 & 1 & 1 & 4 & 9.09 & 25.00 \\
\hline & $\sum$ Satır & 41 & 26 & 79 & 26 & 11 & 183 & & \\
\hline
\end{tabular}

a)

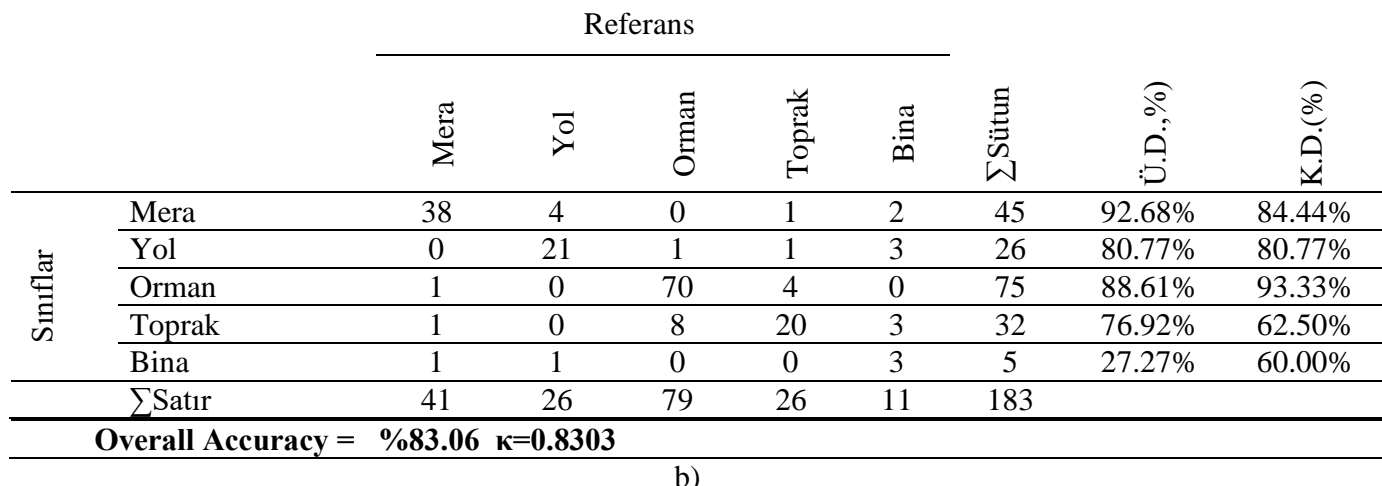


Bunun yanında indirgenmiş hiper bantlı görüntü için aynı analiz yapıldığında PC_DHYP_GPAN ve GS_DHYP_GPAN kaynaştırılmış görüntüleri sınıflandıran RO' nun hata matrislerinde sirasiyla $\% 83.06$ ve $\%$ 81.97 genel sınıflandırma doğrulukları ve $\kappa$ (0.83), $\kappa(0.82)$ kappa olarak elde edilmiştir. DVM' nin hata matrislerine bakıldığında aynı görüntüler için sırasıyla \%70.49 ve \% 71.58 genel sinıflandırma doğrulukları ve $\kappa(0.70)$, $\kappa$ (0.71) kappa olarak elde edilmiştir. Benzer şekilde bu RO daha iyi performans sergilemiştir. Çalışma alanının benzer spektral özellikteki sınıfları barındırması sınıflandırma sonuçlarını olumsuz etkilemiş; ancak genel olarak analiz sonuçlarından da anlaşıldığı gibi hiper bantlı görüntünün kullanılması genel sınıflandırma doğruluğunu önemli oranda (\%11) artırmıştır (Tablo 2).

Hata matrisleri incelendiğinde; spektral özellikleri birbirine yakın sınıflarda karışmalar olduğu gözlenmiş̧tir. Bölge toprak ve beton yollar, beton binalar çimenlik mera alanları, topraklaşmaya yüz tutmuş mera alanları, sık ve seyrek orman alanları gibi kendi içinde farklı karakteristikteki sınıfları barındırmaktadır. Bu nedenle de yol sinifi, bina sinifi ile, toprak sinıfi orman, mera ve yol ile, mera sinıfi orman ile karışmalar göstermiştir.

Tablo 2. Genel Sinıflandırma Doğrulukları a) DHYP_GPAN, b) GMS_GPAN

\begin{tabular}{llll}
\hline & & $\begin{array}{l}\text { Genel } \\
\text { Doğruluk (\%) }\end{array}$ & Kappa \\
& & 71.58 & 0.7158 \\
\hline DVM & GS & 71.58 & 0.7047 \\
& PC & 70.49 & 0.8194 \\
\hline RO & GS & 81.97 & 0.8303 \\
& PC & 83.06 & \\
\hline
\end{tabular}

a)

\begin{tabular}{llll}
\hline & & Genel & Kappa \\
& & Doğruluk (\%) & \\
\hline DVM & GS & 65.03 & 0.6497 \\
& PC & 65.57 & 0.6353 \\
\hline RO & GS & 69.40 & 0.6933 \\
& PC & 72.13 & 0.7208 \\
\hline
\end{tabular}

b)
Özellikle Göktürk-2 görüntüsünün bant sayısının az olması bu sinıfları birbirinden ayırmada yeterli olmamıştır. $\mathrm{Bu}$ nedenle sinıflandırma doğruluğu daha düşük olarak elde edilmiştir. Hiper bantlı görüntü kullanımı ile bu suniflar birbirinden daha iyi ayırt edilmiştir. Göktürk-2 ve Hiper bantlı görüntülerinin RO'ya göre elde edilen üretici ve kullanıcı doğrulukları incelendiğinde; hiper bantlı görüntü birbiriyle en çok karışan mera sinıfinı $\% 15$, yol sinifinı $\% 13$ ve toprak sınıfını \%48 daha iyi temsil etmiştir. Kullanıcı doğruluklarında ise yine hiper bantlı görüntü mera sinifin $1 \% 23$, toprak sinifin $1 \% 33$, orman sınıfinı $\% 7$ ve bina sinıfinı $\% 5$ daha doğru sınıflandırmıştır (Şekil 7). Dolayısıyla en yüksek sınıflandırma doğruluna sahip tematik görüntüden ArcGIS yazılımında üretilen sonuç ürün olan arazi kullanım haritasının kalitesi artırılmıştır (Şekil 8).

\section{SONUCLAR}

Çalışmada en yüksek sınıflandırma doğruluğu, PC kaynaştırma yöntemine göre kaynaştırılmış görüntülerin, RO sinıflandirıcisı ile sınıflandırılması sonucu elde edilmiştir. PC ile kaynaştırılmış Görktürk-2 MS ve PAN görüntüsünün RO ile sınıflandırılması sonucu doğruluk \% 72.13 olarak elde edilmiştir. PC ile kaynaştırılmış indirgenmiş Hyperion EO- 1 ve Görktürk-2 PAN görüntüsünün, RO siniflandiricisı ile de \%83.06 genel sınıflandırma doğruluğuyla sinıflandırıldığı gözlenmiştir. Bu sonuçlara göre \% 11 oranında sinıflandırma doğruluğu artırılmıştır.

Sonuç olarak bu çalışma özellikle spektral olarak yakın özellikteki alanların arazi kullanım haritalarının oluşturulmasında, Göktürk-2 ve hiper bantlı Hyperion EO- 1 uydu görüntülerinin RO sinıflandırıcisı ile birlikte kullanımındaki başarısını ortaya koymaktadır. 


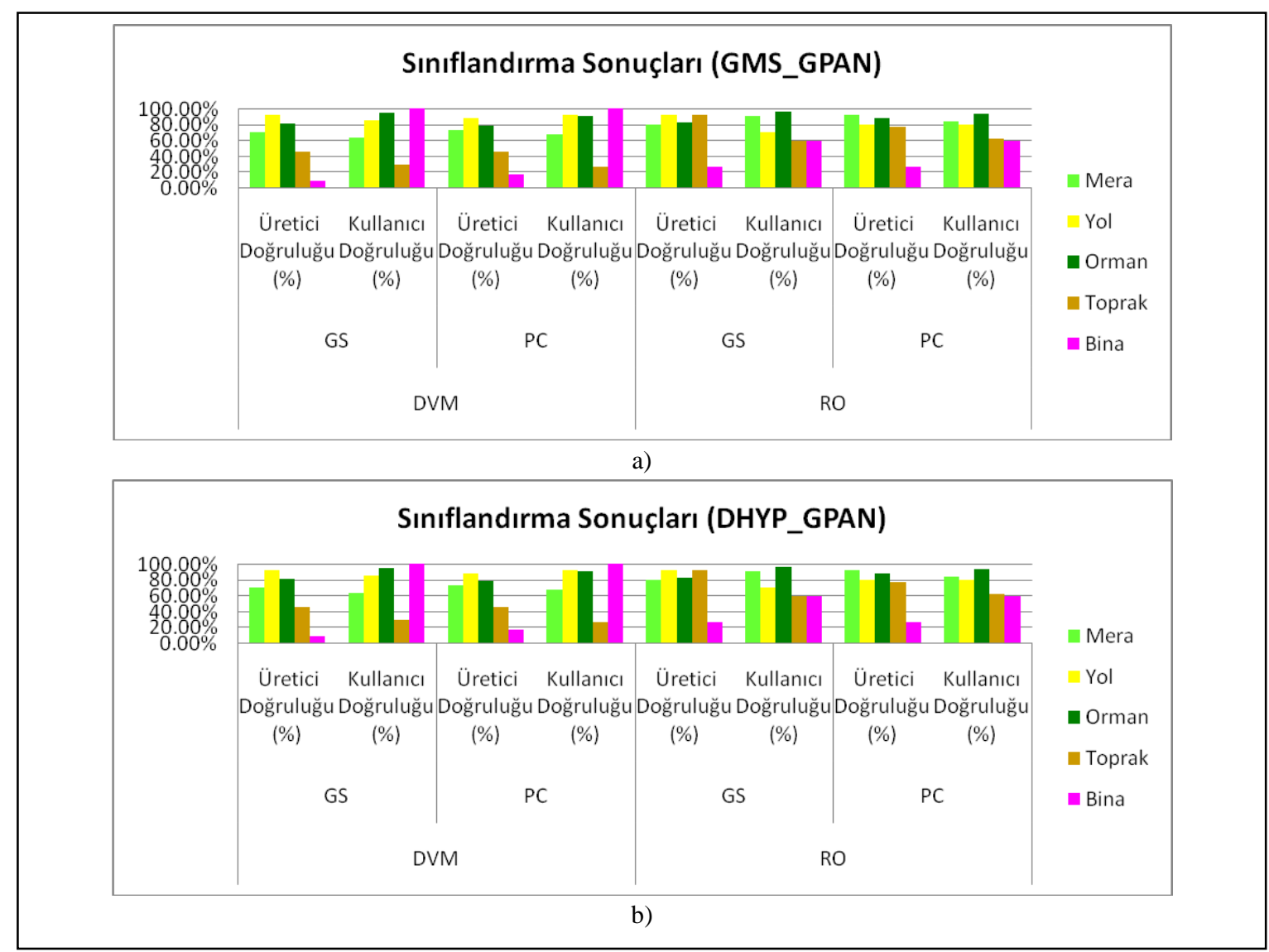

Şekil 7.Üretici ve kullanıcı doğrulukları a)GMS_GPAN, b)DHYP_GPAN

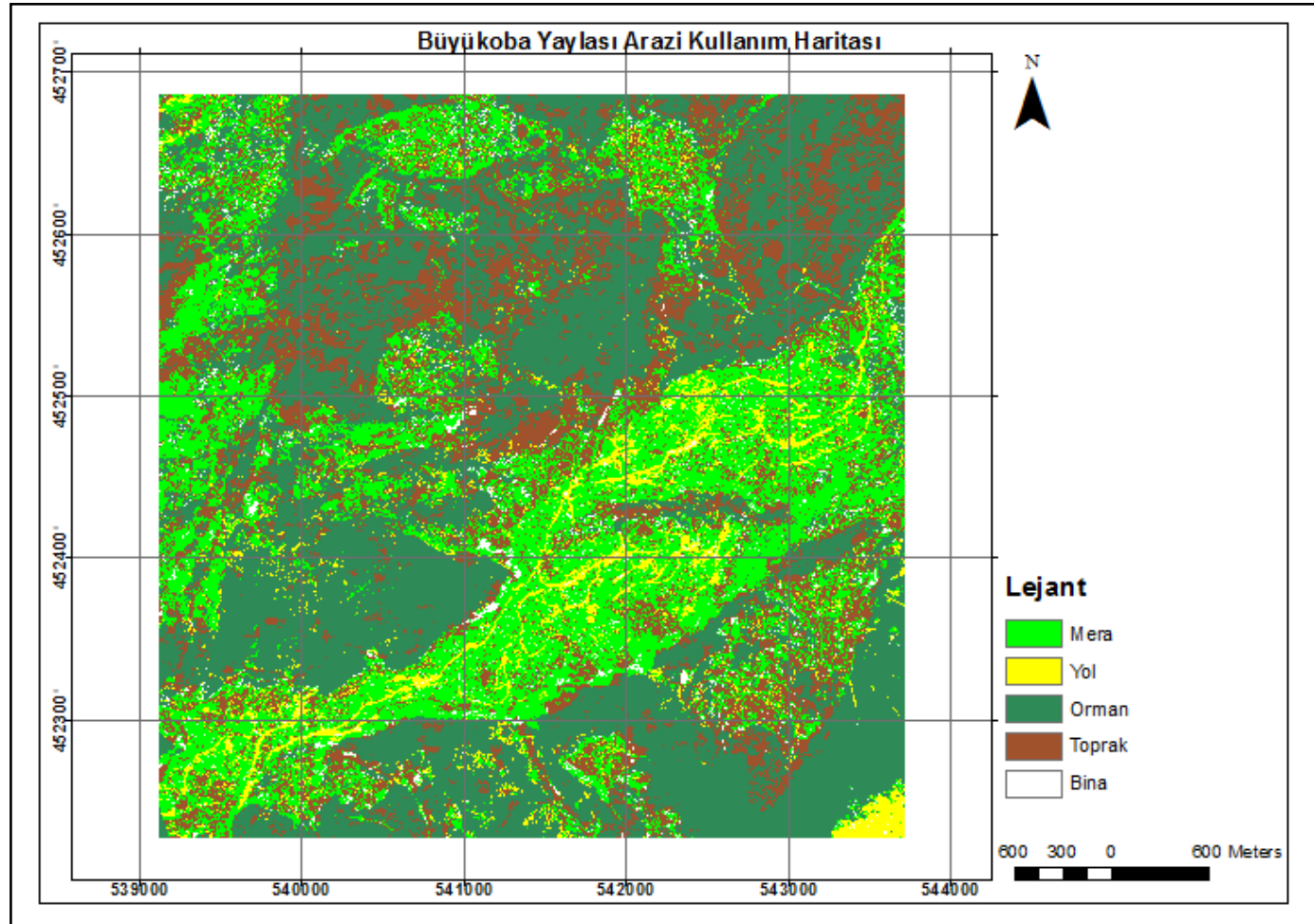

Şekil 8.Arazi kullanım haritası 


\section{Teşekkür}

Çalışmada kullanılan Göktürk-2 uydu görüntülerinin temin edildiği Hava Kuvvetleri Komutanlığı' na ve Worldview2 uydu görüntüsünü sağlayan Karadeniz Teknik Üniversitesi Harita Mühendisliği bölümüne teşekkür ederim.

\section{KAYNAKÇA}

Abbak, A. (2007). Jeodezide Zaman Dizilerinin Dalgacik (Wavelet) Analizi. Doktora Semineri. Selçuk üniversitesi, Jeodezi ve Fotogrametri Mühendisliği Anabilim Dalı Konya.

Akar, Ö., ve Güngör, O. (2015). Integrating multiple texture methods and NDVI to the random forest classification algorithm to detect tea and hazelnut plantation areas in northeast Turkey, International Journal of Remote Sensing, 36, 442- 464.

Archer, K. J. (2008). Emprical characterization of random forest variable importance measure, EDMputational Statistics \& Data Analysis, 52(4), 2249-2260.

Başak, H., Yıldırım, M.A. (2017). Göktürk-2 Uydu Görüntüsünün Otomatik Detay Çıkarımında Kullanılabilirliğinin Araştırılması "Eskişehir İli Örneği" TMMOB Harita ve Kadastro Mühendisleri Odas1, 16. Türkiye Harita Bilimsel ve Teknik Kurultayı, 3-6 Mayıs 2017, Ankara.

Belward A.S. ve Skoien, J.O. (2015) "Who launched what, when and why; trends in global land-cover observation capacity from civilian earth observation satellites," ISPRS Journal of Photogrammetry and Remote Sensing, vol. 103, no. May 2015, 115-128, 2014.

Breiman, L. (2001). Random Forests,Machine learning, Kluwer Academic Publishers, 45(1), 5-32.

Breiman, L. ,(2002). Manual On Setting Up, Using, And Understanding Random Forests V3.1, http://oz.berkeley.edu/users/breiman/Using _random_forests_V3.1.pdf (06.11.2009)

Breiman, L. ve Cutler, A.. (2005). Random Forest, http://www.stat.berkeley.edu/ breiman/Ran domForests/ cc_home.htm (15.11.2009).

Chen, C. H. (2008). Image Processing For Remote Sensing, CRS Press, Taylor\&Francis Group, USA.

Çölkesen, İ. ve Yomralığlu, T. (2014). Arazi Örtüsü ve Kullanımının Haritalanmasında WorldView-2 Uydu Görüntüsü ve
Yardımc1 Verilerin Kullanımı, Harita Dergisi ,Temmuz 2014 (152): 12-24.

Immitzer, M., Vuolo, F. ve Atzberger, C. (2016) First Experience With Sentinel-2 Data for Crop and Tree Species Classifications in Central Europe. Remote Sens. 2016, 8, 166.

Inglada, J., Arias, M., Tardy, B., Hagolle, O., Valero, S., Morin, D., Dedieu, G., Sepulcre, G., Bontemps, S., Defourny, P., (2015). Assessment of an Operational System for Crop Type Map Production Using High Temporal and Spatial Resolution Satellite Optical Imagery. Remote Sens. 2015, 7, 12356-12379.

Kalkan, K., Orhun, Ö., Filiz, B. ve Teke, M. (2015). Vegetation Discrimination Analysis from Göktürk-2, in Recent Advances in Space Technologies (RAST), 2015 7th International Conference on, 2015.

Kavzoglu, T. ve Colkesen, I. (2009), A kernel functions analysis for support vector machines for land cover classification, International Journal of Applied Earth Observation and Geoinformation, 11(5): 352- 359.

Lahat, D., Adali, T. ve Jutten, C., (2015). Multimodal Data Fusion: An Overview of Methods, Challenges, and Prospects, in Proceedings of the IEEE, vol. 103, no. 9, pp. 1449-1477, Sept.

Liaw, A. ve Wiener, M. (2002). Classification And Regression By Random Forest, R News, Vol.2/3, December.

Lillesand, T. M., Kiefer R. W. ve Chipman J. W., 2004. Remote Sensing and Image Interpretation, Wiley, United States of America, 804.

Mather, P. M. (2004). EDMputer Processing of Remotely-Sensed Images: An Introduction, Third edition, Wiley, USA, ISBN 0-470$84918-5$

Özkan, Y. (2008). Veri Madenciliği Yöntemleri, Papatya Yayıncilık, İstanbul.

Pal, M. (2005). Random Forest Classifier For Remote Sensing Classification, International Journal of Remote Sensing, 26(1), 217-222.

Richards, J.A. ve Jia, X. (2006). Remote Sensing Digital Image Analysis: An Introduction 4th Edition, Springer-Verlag, Germany, ISBN-10: 3-540-25128-6.

Srivastava, P.K., Han, D., Rico-Ramirez, M.A., Bray, M. ve Islam, T. (2012) Selection of Classification Techniques for Land Use/land Cover Change Investigation. Adv. Space Res., 50, 1250-1265.

Stephens, D. ve Diesing, M. (2014). A Comparison of Supervised Classification Methods for the Prediction of Substrate Type Using 
Multibeam Acoustic and Legacy GrainSize Data. Magar V, ed. PLoS ONE.;9(4):e93950.

Tardy, B., Inglada, J. ve Michel, J. (2017). Fusion Approaches for Land Cover Map Production Using High Resolution Image Time Series without Reference Data of the Corresponding Period, Remote Sensing, 9, 1151.

Teke, M. (2016). Satellite Image Processing Workflow for Rasat and Göktürk-2, Journal of Aeronautics and Space Technologies, Volume 9 Number 1.

Thanh Noi, P. ve Kappas, M. (2018). Comparison of Random Forest, k-Nearest Neighbor, and Support Vector Machine Classifiers for Land Cover Classification Using Sentinel-2 Imagery, Sensors (Basel, Switzerland). 2018;18(1):18.

Vapnik, V.N. (1995). The Nature of Statistical Learning Theory, Springer-Verlag, New York

Watts, J. D., Powell, S.L., Lawrence, R. L. ve Hilker, T. (2011). Improved Classification of Conservation Tillage Adoption Using High Temporal And Synthetic Satellite Imagery, Remote Sensing of Environment 115 (2011) 66-75 